\title{
Renato Ortiz e o Métier do Sociólogo
}

\section{6}

Renato Ortiz and the Sociologist Métier

Elide Rugai Bastos ${ }^{* *}$

* Recebido em: 04.03.2019. Apovado em: 24.06.2019. Este texto foi apresentado em agosto de 2017 na merecida homenagem prestada pela ECA-USP a Renato Ortiz, intelectual importante, colega de trabalho e querido amigo.

** Professor do Programa de PósGraduação em Sociologia da

Universidade Estadual de Campinas e do Pós-Graduação em Sociologia da Universidade Federal de São Paulo. Email:
Resumo: a questão que encaminho neste artigo é a seguinte: como Renato Ortiz analisa o métier do sociólogo, tema a que se dedica, a partir de diferentes ângulos. Primeiro abordo como esse autor define o trabalho intelectual; segundo, como desenha o perfil das Ciências Sociais.

Palavras chave: sociologia; ciências sociais; trabalho intelectual; interdisciplinaridade; pensamento social brasileiro.
Abstract: the question that I address in this article is the following: how does Renato Ortiz analyses the sociologist métier from different angles. First I approach how this author defines intellectual work; second, how is the profile of the social sciences.

Keywords: Sociology; Social Sciences; Intellectual Work; Interdisciplinarity; Brazilian Social Thought. 
${ }^{1}$ Tive a oportunidade de discutir sobre vários elementos aqui abordados em texto publicado em Tempo Social., USP, São.Paulo, $14(20$, p. $209-212,2002$
A ampla e diversificada produção de Renato Ortiz, que tem sido ponto de partida e de indagações para muitos pesquisadores, já foi assinalada e analisada em vários textos. Assim, vou limitar minhas considerações a um aspecto em sua reflexão que chama minha atenção: a discussão sobre o métier do sociólogo, tema a que se dedica, a partir de diferentes perspectivas, em artigos e livros.

$\mathrm{Na}$ abordagem desse papel específico, o autor analisa duas fases: primeiramente, a definição sobre o trabalho intelectual; segundo, desdobra o estudo na definição do perfil das Ciências Sociais. As duas etapas são vistas de modo articulado, isto é, dedica-se a definir o significado do trabalho intelectual no campo das Ciências Sociais.

O tema chama minha atenção obviamente por si mesmo, mas também porque seu desenvolvimento expressa o método de exposição que caracteriza grande parte dos textos de Renato Ortiz. Na definição de trabalho, trabalho intelectual, o primeiro objetivo desse autor é mostrar que se trata de um fazer, um procedimento que carrega consigo a qualidade artesanal. Assim, antes de tudo torna-se necessário reconstruir o processo de constituição do tema a ser estudado: a qualidade artesanal determinando que seja uma construção "pedaço por pedaço", mas tendo como referência o produto final, ou melhor, que se caracterize por inferir a totalidade. Sendo trabalho intelectual na área das Ciências Sociais, cada pesquisa coloca perguntas específicas e visões interpretativas a partir de vários ângulos. Não só as questões são definidas considerando-se tanto o lugar em que o pesquisador se coloca como a perspectiva analítica que caracteriza esse lugar. Por isso, segundo assinala o autor, a prática sociológica requer vários passos que se sucedem: investigação bibliográfica, pesquisa empírica, busca de fontes primárias, leituras diversas, anotações, seleção de material, elaboração de conceitos, definição da exposição, escritura. Trata-se de tarefa árdua.

Nesse procedimento define o trabalho intelectual a partir de dois aspectos: pelo que é e pelo que não é. Primeiramente, é um projeto, uma ação deslocada para o futuro na qual o indivíduo se realiza. Nesse sentido tratase de um trabalho único e singular. Carrega consigo a ideia de incompletude, pois a próxima reflexão tem o poder e o dever de acrescentar, criticar, inovar. Mas, ao mesmo tempo, não é um trabalho que pode ser 
mensurado, ser avaliado a partir da quantificação. Não pode ser confundido com a comercialização das ideias ou com a burocratização do pensamento. Embora a intenção crítica não esteja explícita nessa abordagem, resulta numa reflexão que condena a fragmentação desses objetivos, ocorrência comum nos dias de hoje: produzir em massa para aumentar os índices de produção bibliográfica, não levando em conta que o resultado seja mais do mesmo.

\section{Ciências Sociais como visão ampla}

Porque Renato fala mais amplamente sobre as Ciências Sociais e não apenas sobre a Sociologia? Porque lembra que os conceitos são lapidados a partir de múltiplos instrumentos analíticos. Disso decorre sua visão de articulação das diversas áreas das Ciências sociais. Trata-se da negação da fragmentação destas, da afirmação de um diálogo que persiste apesar das mudanças operadas nas estruturas universitárias, das inúmeras políticas oficiais orientadoras da pesquisa que se apresentaram ao longo do tempo. Em outras palavras, aponta a importância de uma multiplicidade disciplinar que não se reduz à engenharia social, mas que se afirma como crítica.
Trata-se de uma visão que se opõe a certa orientação que tem atingido a avaliação em Ciências Humanas que não só quantifica como valoriza a superespecialização. Lembro uma palavra oficial que se refere tanto à necessidade de pertencimento exclusivo do pesquisador a uma área em termos de formação, pesquisa, docência, produção, orientação, como à principal qualidade a lhe ser atribuída - aderência. Talvez porque minha formação seja um pouco antiquada, parece-me um termo de caráter patológico, pois é o nome que o dicionário médico atribui a uma "união viciosa de órgãos ou superfícies, oriunda de fenômenos inflamatórios ou alterações degenerativas". Assim, minha interpretação a partir dessa ótica leva-me a considerar, na área de ciências sociais, a atuação exclusivamente dentro de um campo certo caminho de superespecialização em detrimento de conhecimento amplo.

A aceitação de um pluralismo que admite a superposição das fronteiras das diferentes disciplinas da área das ciências humanas indica a qualidade crítica que caracteriza as Ciências Sociais. É o que permite o rompimento com o senso comum, ou seja, a depuração das noções do senso comum transformando-as em 
2 Esse memorial será retomado e publicado mais tarde: Ortiz, Renato. Trajetos e memórias. São Paulo: Brasiliense, 2010. abstrações mais complexas, capazes de funcionar como categorias analíticas da vida social. É claro que esse traço resulta numa dupla tensão, pois compreende dois movimentos: de um lado procura-se apreender a realidade; de outro, busca-se distanciar da realidade imediata, construindo outra espacialidade que abre espaço ao pensamento analítico/crítico. Em outras palavras, essa operação promove a percepção além da aparência, a revelação do oculto, a ultrapassagem das consciências individuais.

É certo que as ciências sociais puderam desenvolver-se e sistematizar-se, como lembra Renato, porque se construiu um campo com claras definições e funções institucionais - universidades, centros de pesquisa, editoras, revistas - que permitem o debate, a troca de ideias, de resultados de pesquisas, a difusão do conhecimento. Se essa ampliação foi fundamental, de outro lado surge o risco de alimentar uma lógica mercantil, alheia ao trabalho acadêmico, muitas vezes submetido ao mundo midiático.

Tendo como ponto de partida as questões acima levantadas, Renato orienta seus textos sobre essa temática supondo a necessidade da interdisciplinaridade, isto é, do diálogo da sociologia com as outras áreas das ciências sociais. Nessa direção reconstrói temas e polêmicas nos vários momentos da história. Figuram, assim, nesse debate a questão dos intelectuais, do mercado, da mídia, além da institucionalização que marca em geral a reconstituição do percurso da sociologia, mostrando o peso diverso desses fatores nos diferentes contextos espaciais e temporais. Abre-se, portanto, à abordagem da internacionalização das ciências sociais no quadro da globalização. Nesse cenário marcado por alterações temáticas e novas questões, indaga como se redefine o papel dos intelectuais.

\section{O pensamento social}

Esses questionamentos levam, obviamente, o autor a refletir sobre a produção do pensamento social e à pergunta: nesse amplo quadro, há lugar para as ciências sociais brasileiras? E qual é ele? Essas questões exploradas em vários textos aparecem com ênfases diversas nos diferentes momentos do percurso intelectual de Renato Ortiz, como podemos perceber em seu memorial da livre-docência apresentado ao concurso da Unicamp. ${ }^{2}$ Os temas "autonomização das ciências sociais 
no Brasil" e "o papel dos intelectuais" ganham corpo nesse texto. Falando sobre sua própria formação na "tradição da escola francesa considerava a Sociologia e a Antropologia como habitantes do mesmo território acadêmico" (ORTIZ, 2010, p. 86), considera que os fenômenos sociais devem ser apreendidos em sua integridade, não pertencendo exclusivamente a nenhuma disciplina. Desse modo, na análise do processo de autonomização das ciências sociais, que no Brasil se inicia entre 1940 e 1950, mostra a ocorrência de uma fragmentação disciplinar que se configura na separação dos departamentos de sociologia, antropologia e ciência política nas universidades, a qual não deveria afetar necessariamente a análise integradora se operasse no sentido interdisciplinar. Infelizmente tal prática não foi oficialmente implementada e não é a mais usual.

A discussão do papel dos intelectuais se segue a essa exposição. Novamente, no Brasil a abordagem clássica sobre os intelectuais foi iniciada tardiamente se comparada ao processo de autonomização dessa figura que se consolida ao longo do século XVIII. Isto é, a Europa desse período pode ver o intelectual como figura social, pública, dotado de certa autonomia e razão crítica em relação aos poderes constituídos - Igreja, clero, nobreza, estados absolutistas. Com essa categoria, não nomeada especificamente como intelectual, surge a crítica social. Trata-se de um momento especial de transformação da sociedade quando se consolida um espaço público e, consequentemente, uma opinião pública. Nesse horizonte emergem estudos específicos sobre a sociedade e se configura a sociologia.

Em vários artigos e apresentações, Renato Ortiz abordou aspectos que envolvem essa temática, ou seja, o surgimento e consolidação do pensamento social. Fixome, especialmente, no livro Ciências Sociais e trabalho intelectual, publicado em 2002, no qual um conjunto de questões sobre a produção do pensamento social ganha corpo na análise da forma pela qual os autores dialogam com seu tempo, com seus precursores e buscam, direta ou indiretamente, soluções para as questões sociais. Tanto quando aborda textos de Durkheim, Benjamin, Escola de Frankfurt, Bourdieu, como no balanço sobre as ciências sociais no Brasil, para compreendê-los, insere os autores no momento em que produzem, recupera seu diálogo com intérpretes anteriores e aponta as diferentes fases de seu pensamento. Tomo como exemplo o livro As Formas 


\section{Elide Rugai Bastos}

Elementares da Vida Religiosa, de Durkheim. A questão das continuidades e descontinuidades da argumentação desse sociólogo contraposta a seus escritos anteriores na análise de Renato não está referida apenas a um problema de lógica interna da proposta durkheimiana, como usualmente se aponta, mas direciona-se à forma pela qual esse autor opera na reorganização dos conceitos. O procedimento se aplica, também, em relação aos outros intelectuais estudados, pois faz um balanço das contribuições dos diferentes cientistas sociais que os precederam.

Além disso, analisando os autores que produziram no passado, indaga sobre a contemporaneidade de sua obra, a qual não reside apenas na permanência dos temas, mas principalmente na abertura dos mesmos para uma abordagem nova que amplie o âmbito das ciências sociais. No exemplo dado acima, Renato mostra que o texto de Durkheim é mais amplo do que um estudo apenas sobre a religião: abre-se para a temática da ideologia. Assim, permite descortinar um campo novo de reflexões que consistirá em temática da sociologia contemporânea, da sociologia do conhecimento. Durkheim, ao colocar o problema da apreensão do mundo - a representação - permite o desdobramento da indagação em dois eixos, forma e conteúdo, o que é pensado e o modo de pensar. Simultaneamente a retomada de um problema colocado no passado para a filosofia e seu reflexo futuro para a sociologia.

Estes são alguns pontos, entre inúmeros outros, nos quais reconheço a importância da reflexão de Renato Ortiz para o estudo da sociologia. A homenagem que se prestou e na qual apresentei este breve comentário é uma expressão do papel importante que como pesquisador, professor, orientador e autor ele tem representado para as ciências sociais.

\section{Referências}

DURKHEIM, Emile. As Formas Elementares da Vida Religiosa. SP: Paulínea, 1989

ORTIZ, Renato. Trajetos e Memórias. São Paulo: Brasiliense: 2010. 